\title{
Tropical Pacific influences on the North Atlantic Thermohaline Circulation
}

\author{
Mojib Latif \\ Max-Planck-Institut für Meteorologie, Hamburg, Germany
}

\begin{abstract}
Most global climate models simulate a weakening of the North Atlantic Thermohaline Circulation (THC) in response to enhanced greenhouse warming. Both surface warming and freshening in high latitudes, the so-called sinking region, contribute to the weakening of the THC. Some models simulate even a complete breakdown of the THC at sufficiently strong forcing. Here results from a state-of-the-art global climate model are presented that does not simulate a weakening of the THC in response to greenhouse warming. Large-scale air-sea interactions in the tropics, similar to those operating during present-day El Niños, lead to anomalously high salinities in the tropical Atlantic. These are advected into the sinking region, thereby increasing the surface density and compensating the effects of the local warming and freshening. The results of the model study are corroborated by the analysis of observations.
\end{abstract}

Key words thermohaline circulation - air-sea interactions - climate variability

\section{Introduction}

The Atlantic Thermohaline Circulation (THC) is an important component of the global climate system (Broecker, 1991). It transports about $1 \mathrm{PW}$ of heat poleward in the North Atlantic, thereby warming Western Europe. The THC is forced partly by convection at high latitudes, which causes dense surface waters to sink to deeper ocean layers, forming the so-called North Atlantic Deep Water (NADW). Strong and rapid changes in the intensity of the NADW formation have been reported from paleoclimatic records (Broecker et al., 1985), and it is well established that such changes exert a strong impact on the climate over large land areas (e.g., Manabe and Stouffer, 1995, 1999; Schiller et al., 1997).

Mailing address: Dr. Mojib Latif, Max-Planck-Institut für Meteorologie, Bundesstr. 55, D-20146 Hamburg, Germany; email: latif@dkrz.de
Several papers have suggested that the thermohaline circulation may weaken in response to greenhouse warming (e.g., Mikolajewicz et al., 1990; Manabe et al., 1991; Stocker and Wright, 1991; Cubasch et al., 1992; Manabe and Stouffer, 1994; Rahmstorf, 1997, 1999; Wood et al., 1999). Here, we investigate the sensitivity of the THC to greenhouse warming using a global climate model that has been applied in various climate variability and response studies (Roeckner et al., 1996; Bacher et al., 1997; Oberhuber et al., 1998; Timmermann et al., 1999; Roeckner et al., 1999; Christoph et al., 1998; Ulbrich and Christoph, 1999). It is shown that the tropical feedbacks associated with an increased El Niño frequency can stabilise the THC (Latif et al., 2000).

\section{Model}

The model (ECHAM4/OPYC) is flux-corrected (using annual mean corrections) with respect to heat and freshwater. The application of flux correction reflects serious errors in the individual model components. The effects of flux correction on the response characteristics of a model are largely unknown, but it has been 
shown that flux correction may cause misleading results (e.g., Neelin and Dijkstra, 1995). It should be noted, however, that many studies addressing the stability of the THC have been conducted with flux-corrected models (e.g., Manabe and Stouffer, 1994).

Our model employs a horizontal resolution over most of the globe of $2.8^{\circ} \times 2.8^{\circ}$. A special feature of the model is the higher meridional resolution of $0.5^{\circ}$ used in the tropical oceans, which enables a realistic simulation of the El Niño/Southern Oscillation (ENSO) phenomenon (Roeckner et al., 1996; Bacher et al., 1997; Oberhuber et al., 1998), the strongest natural interannual climate fluctuation. We performed two integrations. The first experiment is a 240year long control integration with fixed presentday concentrations of greenhouse gases. In the second experiment the model was forced by increased greenhouse gas concentrations, giving approximately the historical increase in radiative forcing from 1860 to 1990 (Roeckner et al., 1999), and subsequently (up to 2100) by increases according to IPCC scenario IS92a (IPCC, 1992). The effects of anthropogenic sulfate emissions are not included in the simulation.

\section{Results}

The control run simulates the THC in the North Atlantic reasonably well (Zhang et al., 1998), with a maximum overturning of about 23 $\mathrm{Sv}$ at a depth of about $2000 \mathrm{~m}$ and an NADW outflow at $30^{\circ} \mathrm{S}$ of about $15 \mathrm{~Sv}\left(1 \mathrm{~Sv}=10^{6} \mathrm{~m}^{3} / \mathrm{s}\right)$ at a depth of about $1500 \mathrm{~m}$. However, the model fails to simulate the inflow of the very dense Antarctic Bottom Water (AABW) into the North Atlantic. The THC is relatively stable during the control integration, but exhibits some superimposed interdecadal variability (fig. 1). The range of this internal THC variability is consistent with that simulated by other global climate models (Delworth et al., 1993; Timmermann et al., 1998). In the transient greenhouse warming simulation the THC remains also stable, with a slight decrease during the first half and a slight increase during the second half. Thus, our model predicts a stable THC rather than a weakening

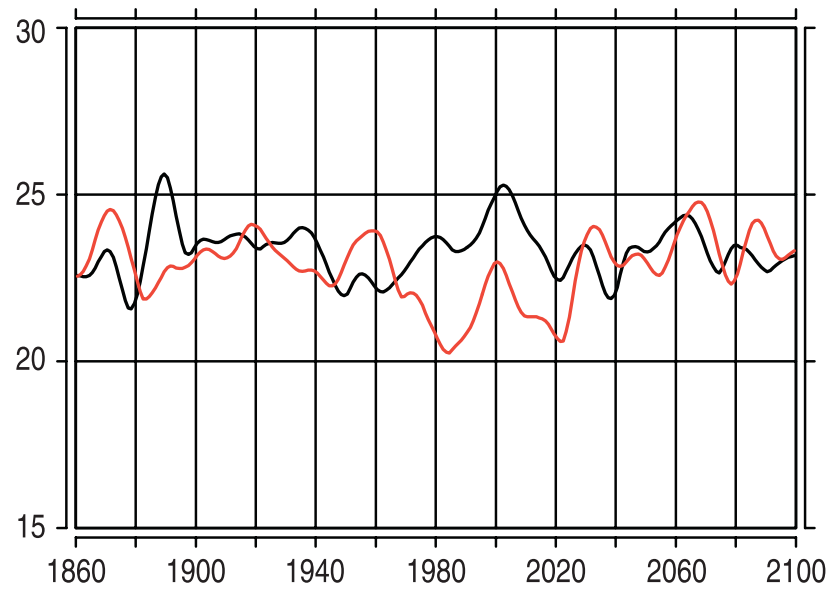

Fig. 1. Time series of the maximum overturning (Sv) in the North Atlantic for the control integration with present-day greenhouse gas concentrations (black line) and the transient greenhouse warming simulation (red line).

THC as simulated by most other global models (Rahmstorf, 1999).

The physics responsible for the stabilisation of the THC in our model is related to tropical air-sea interactions. The regional distribution of the simulated Sea Surface Temperature (SST) trend is characterised by warming in most ocean areas, with some cooling tendency in certain regions around Antarctica (not shown, see also Roeckner et al., 1999). Of particular importance is the El Niño-like warming trend in the eastern equatorial Pacific. As has been described in Timmermann et al. (1999), this warming results from air-sea interactions similar to those producing present-day El Niños and has strong impacts on the entire tropical climate system. The model simulates strongly enhanced precipitation over the central equatorial Pacific (fig. 2), a feature observed during present-day El Niños (Philander, 1990; Ropelewski et al., 1987). This leads to adiabatic warming and drying through anomalous subsidence over Northeast Brazil and the tropical Atlantic, thereby reducing precipitation and river runoff from the Amazon catchment area and increasing evaporation from the tropical Atlantic. The model simulates an additional freshwater export from the Atlantic to the Pacific of about $0.015 \mathrm{~Sv} /$ decade, in comparison to only $0.005 \mathrm{~Sv} /$ decade in another Max- 

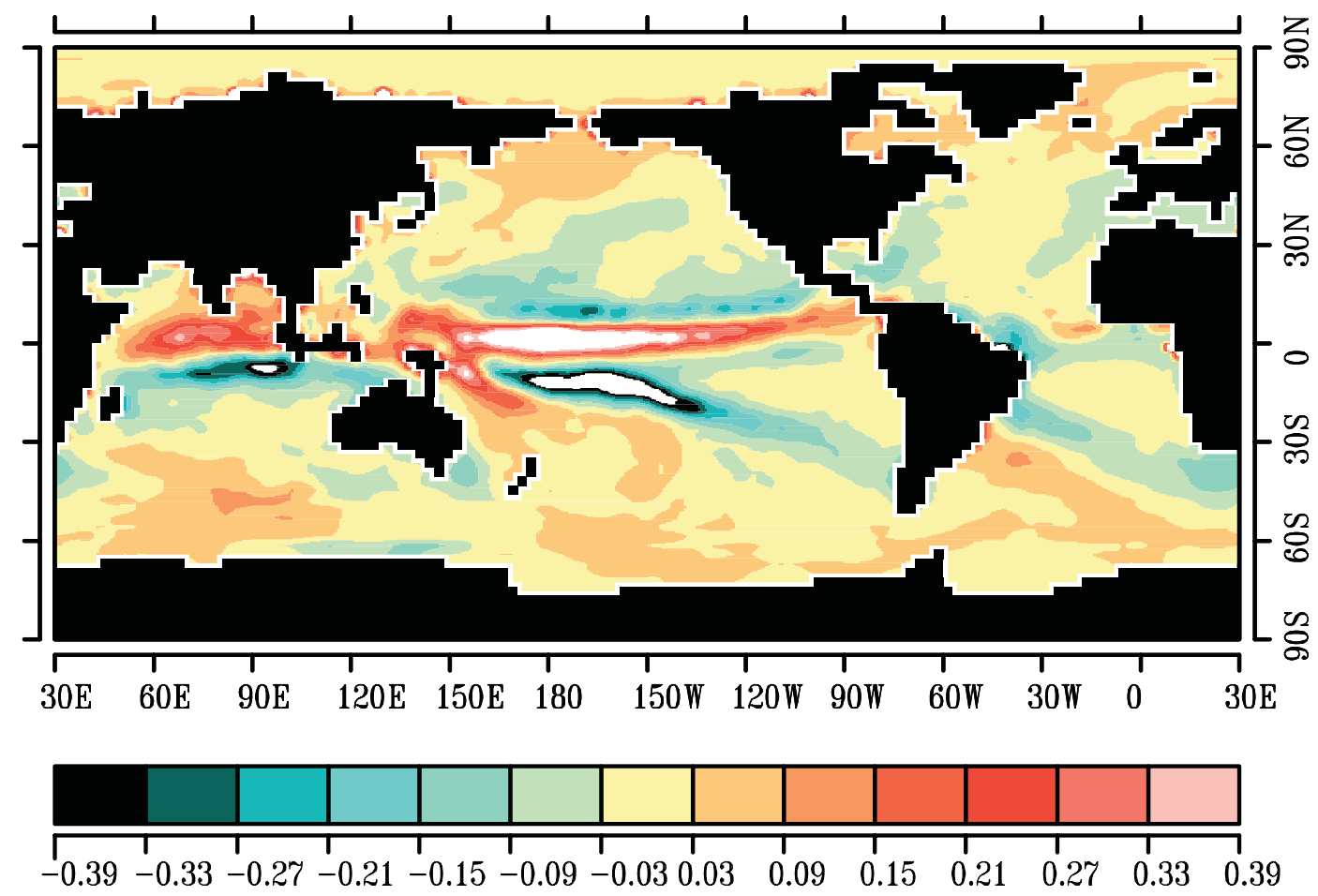

Fig. 2. Centennial linear trend in the freshwater flux $(\mathrm{P}-\mathrm{E}+\mathrm{R}$, precipitation minus evaporation plus river runoff ) $[\mathrm{mm} /(\mathrm{d} *$ decade $)]$ obtained from the transient greenhouse warming simulation and computed over the period 2000-2100. Note the freshening in the equatorial Pacific associated with the increased El Niño frequency and the strongly reduced freshwater influx over the tropical Atlantic.

Planck-Institute coupled model (ECHAM- 3/ LSG) simulating a weakening of the THC (Mikolajewicz and Voss, 2000) as discussed by Rahmstorf (1999: his fig. 2). Such an enhanced freshwater export is also observed during present-day El Niños (Schmittner et al., 2000).

The reduced freshwater flux induces anomalously high salinities in the tropical Atlantic Ocean (fig. 3b). We averaged the freshwater fluxes over two regions $\left(30^{\circ} \mathrm{S}-45^{\circ} \mathrm{N}\right.$ and $45^{\circ} \mathrm{N}$ $90^{\circ} \mathrm{N}$ ) and display their time evolutions in fig. 4a. The freshwater input to the Atlantic towards the end of the integration is strongly reduced by about $0.3 \mathrm{~Sv}$ in the tropical region, while it is enhanced by about $0.1 \mathrm{~Sv}$ in the middle and high latitudes. Thus, the changes in the freshwater flux will tend to enhance the salinity in the tropics and to reduce the salinity in the middle and higher latitudes, with changes in the tropics being considerably stronger in the tropics. We timeintegrated the anomalous freshwater flux forcing into the Atlantic and Arctic poleward of $30^{\circ} \mathrm{S}$.
This quantity has been compared to the anomalous salt content of the upper $375 \mathrm{~m}$ at the end of the integration. The actual salt gain of the upper Atlantic amounts to about two third of the total implied freshwater induced salt gain. We do not expect a perfect match, since the integration domain is not closed. However, this computation shows that the salinity anomalies can easily be explained by the changes in atmospheric moisture transport.

The poleward transport of the salt anomaly and the mixing within the subtropical gyre result in increased surface salinity over the entire North Atlantic Ocean. The poleward propagation of the anomalously high salinities is visualised by a Hovmoeller diagram showing the temporal evolution of the salinity anomalies averaged over the upper $375 \mathrm{~m}$ in a meridional section along $45^{\circ} \mathrm{W}$ (fig. $4 \mathrm{~b}$ ). The salinity transport outweighs the counteracting local freshwater influx through enhanced precipitation (figs. 2 and 4a) and warming in the high latitudes of the North Atlantic 

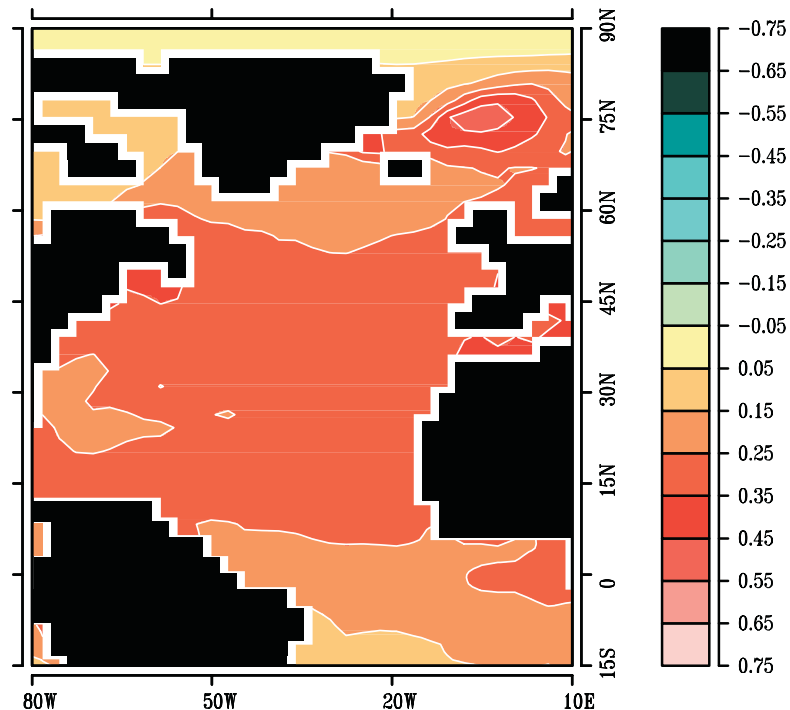

(a)
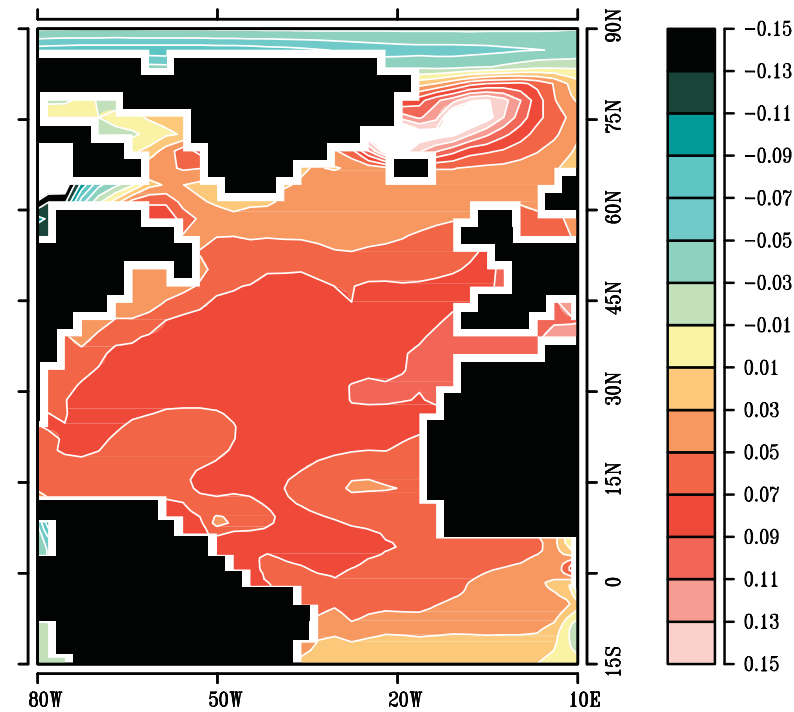

(b)

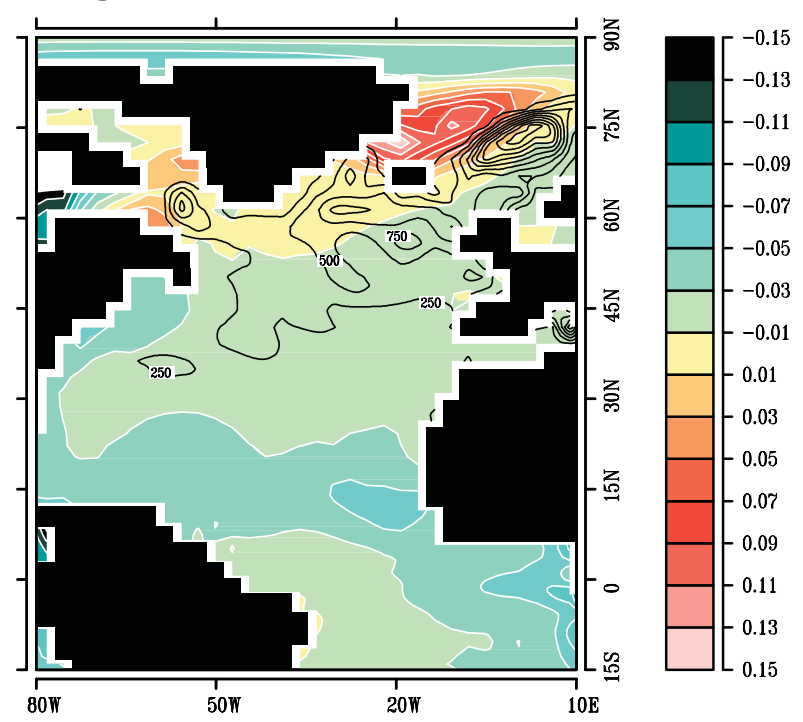

(C) (fig. 3a), which are the principal feedbacks in models predicting a reduced THC.

We computed separately the salt and temperature contributions in the change of the surface density, which is the crucial quantity for deep water formation. The linear expansion coefficients for temperature and salinity for a temperature of $5^{\circ} \mathrm{C}$ and salinity of $35 \mathrm{psu}$, which are characteristic values for the sinking region, amount to $-0.12\left(\mathrm{~kg} / \mathrm{m}^{3}\right) / \mathrm{K}$ and $0.79\left(\mathrm{~kg} / \mathrm{m}^{3}\right) / \mathrm{psu}$, respectively. Given a SST change of about $0.3^{\circ} \mathrm{C} /$ decade and a salinity change of about $0.05 \mathrm{psu}$ (fig. 3a,b) yields comparable density changes of about $0.4 \mathrm{~kg} /\left(\mathrm{m}^{3} *\right.$ decade $)$. A calculation using the complete equation of state yields a similar result, with almost no density change in the regions of strongest deep water formation (fig. $3 \mathrm{c})$. Thus, in our transient greenhouse warming simulation the poleward salt transport is an important feedback process, in addition to the freshening through increased precipitation and warming in the high latitudes, and the net outcome is a stable rather than a weakening THC.

Are the changes in the hydrological cycle large enough to have a significant effect on the THC? Typical threshold values for a complete collapse of the present-day THC are in the range of 0.1-0.4 Sv for anomalous freshwater input into the North Atlantic (e.g., Stocker and Wright, 1991; Rahmstorf, 1995, Schiller et al., 1997). Given a change of the order of $-0.3 \mathrm{~Sv}$ in our simulation, it is not surprising that this effect is large enough to balance the locally induced weakening of the THC.

Fig. 3a-c. Centennial linear trends of selected quantities in the North Atlantic obtained from the transient greenhouse warming simulation and computed over the period 2000-2100. a) Trend in SST $\left({ }^{\circ} \mathrm{C} /\right.$ decade $\left.) ; \mathrm{b}\right)$ trend in sea surface salinity (psu/ decade); c) trend in surface density $\left[\mathrm{kg} /\left(\mathrm{m}^{3} *\right.\right.$ decade $\left.)\right]$. The depth of the convection (m) simulated for the month of February in the control integration is shown as contours (contour interval is $250 \mathrm{~m}$ ). The two main convection regions in the Labrador and GIN (Greenland-Iceland-Norwegian) Seas are simulated realistically by the model. No significant change in the density is simulated in these regions. 


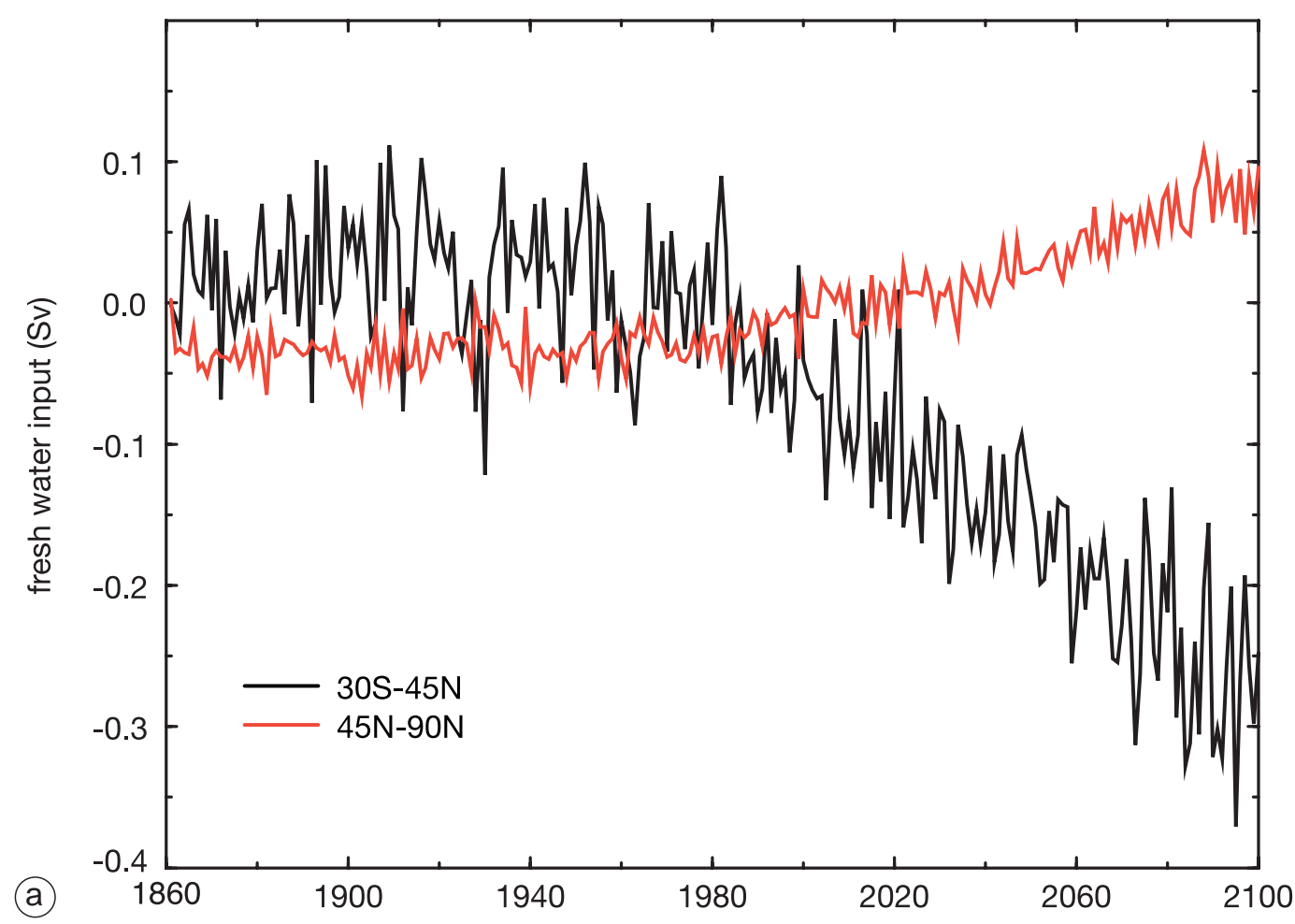

evolution of $S(0-375 m)$ along $45 \mathrm{~W}$, anom. rel. to init. state

(b)

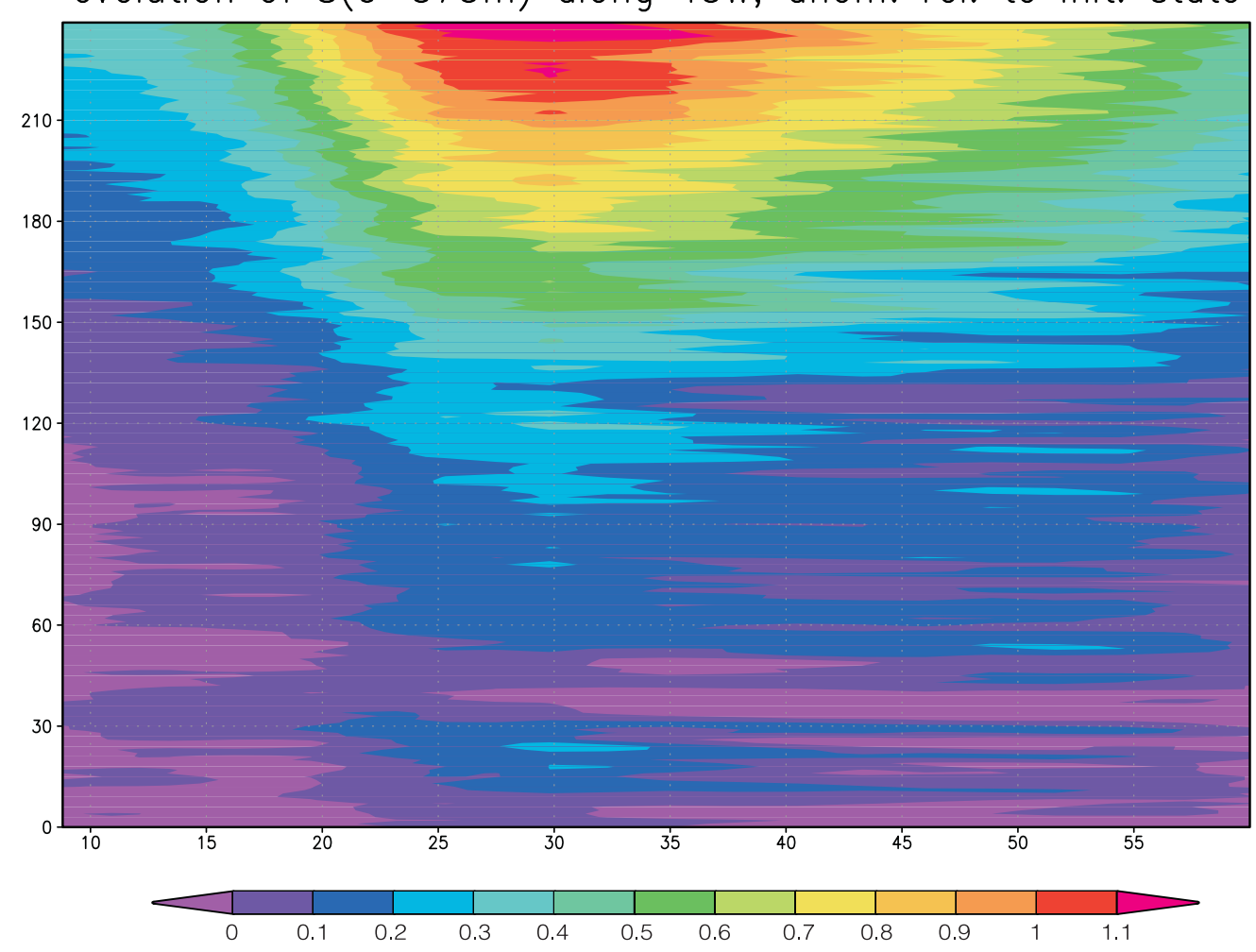

Fig. 4a,b. a) Time series of anomalous freshwater input (Sv) into the Atlantic in the region $30^{\circ} \mathrm{S}-45^{\circ} \mathrm{N}$ (black curve) and into the mid and high latitudes $\left(45^{\circ} \mathrm{N}-90^{\circ} \mathrm{N}\right.$, red curve). b) Temporal evolution of the salinity anomalies (psu) averaged over the upper $375 \mathrm{~m}$ along $45^{\circ} \mathrm{W}$. The northward propagation of the salinity anomalies from the subtropics to higher latitudes can be clearly seen by the tilt of the contours. The anomalies are calculated by subtracting the initial values. 


\section{Further modeling and observational evidence}

Next, simulations with an Atmospheric General Circulation Model (AGCM) and some observations are analysed (Latif, 2001). Unfortunately, long time series of the freshwater flux over the Atlantic are not available from observations. Instead AGCM simulations with observed SSTs prescribed globally for several decades were used to study further the connections between the tropical Pacific and tropical Atlantic Oceans. The tropical atmosphere is highly predictable (e.g., Lau, 1985), and it is believed that such simulations provide useful insights about the nature of the response of the tropical atmosphere to tropical Pacific SST anomalies associated with ENSO-type multidecadal variability. The AGCM used here is ECHAM4 (Roeckner et al., 1996) with T42 resolution $\left(2.8^{\circ} \times 2.8^{\circ}\right)$, a model that has been used in many climate applications (see, e.g., Roeckner et al., 1999). In particular, ECHAM4 served as the atmospheric component of the coupled model ECHAM4/OPYC described above. An ensemble of three AGCM integrations was performed for the period 1903-1994, and the ensemble mean is shown here. The SSTs used to drive the model are the GISST SSTs (Parker et al., 1995). The Kaplan (1997) data set is used in the investigation of the SSTs themselves shown below, since it is the longer data set. However, since the response characteristics of the model do not depend on the forcing SSTs, the use of the different SST data sets in this study is acceptable.

The atmosphere model simulates an out-ofphase relationship between decadal fluctuations in eastern tropical Pacific (Niño-3) SST and the freshwater flux over the tropical Atlantic $\left(10^{\circ} \mathrm{S}\right.$ $30^{\circ} \mathrm{N}$ ) as shown in fig. 5, confirming the observational results of Schmittner et al. (2000). The correlation between the two time series amounts to -0.75 . Furthermore, both the tropical Pacific SST and the simulated freshwater flux exhibit rather strong trends during the last 50 years: while the tropical Pacific SST is slowly increasing by about $0.5^{\circ} \mathrm{C}$, the freshwater flux over the tropical Atlantic is slowly decreasing by about $0.06 \mathrm{~Sv}\left(10^{6} \mathrm{~m}^{3} / \mathrm{s}\right)$ (fig. 5). This be-

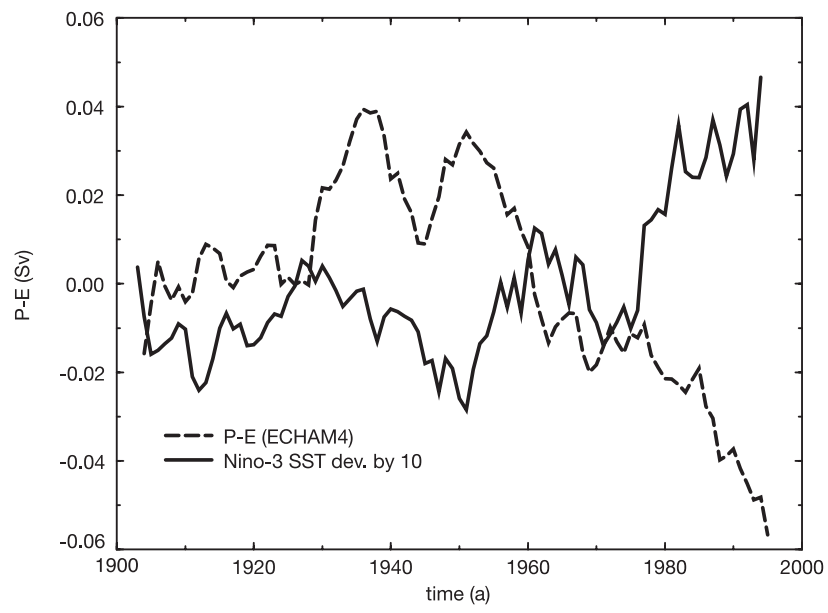

Fig. 5. Time series of the Niño-3 SST anomaly and the anomalous tropical Atlantic freshwater flux as simulated by the ECHAM4 model averaged over the region $10^{\circ} \mathrm{S}-30^{\circ} \mathrm{N}$, which is the region with the most consistent response over the Atlantic. Both time series vary out of phase and exhibit strong trends during the last 50 years. Both time series were filtered with a 11year running mean.

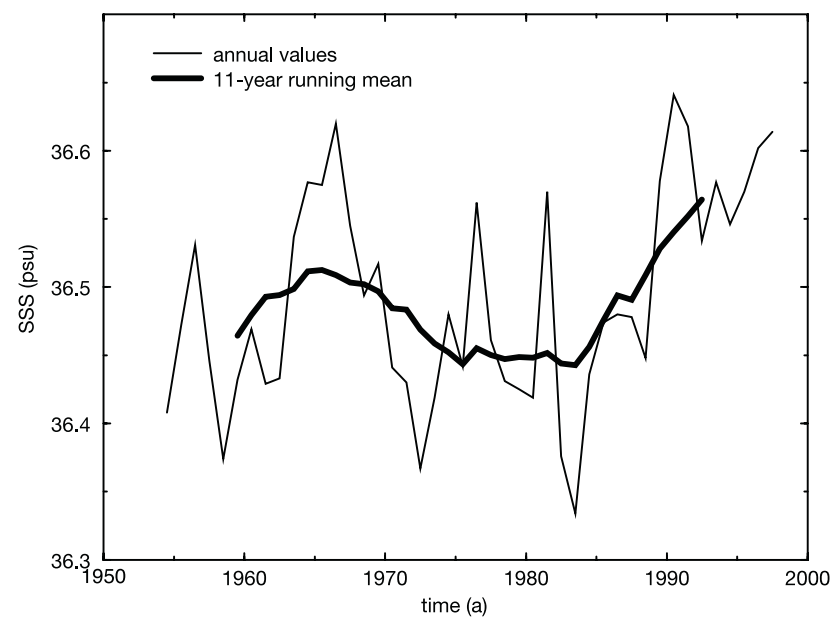

Fig. 6. Time series of the salinity observed at Bermuda $\left(33^{\circ} \mathrm{N}, 65^{\circ} \mathrm{W}\right)$. Please note the strong increase of the salinity during the most recent decades.

haviour is consistent with that found in the greenhouse warming simulation described above and supports the picture that there exists a potential «atmospheric bridge», by which the tropical Pacific and Atlantic Oceans can interact with each other. Further evidence for the existence of the atmospheric bridge comes from 


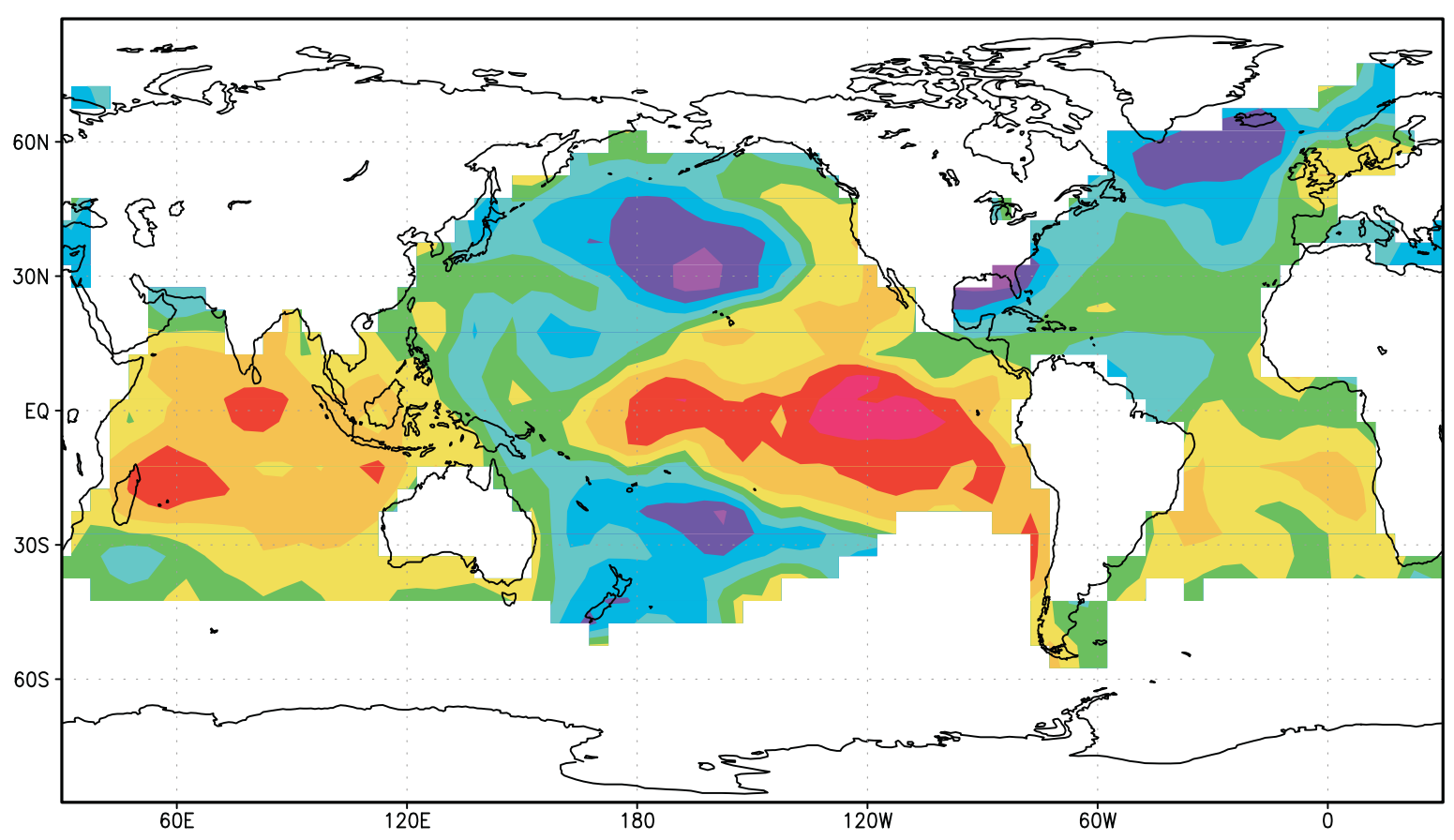

(a)
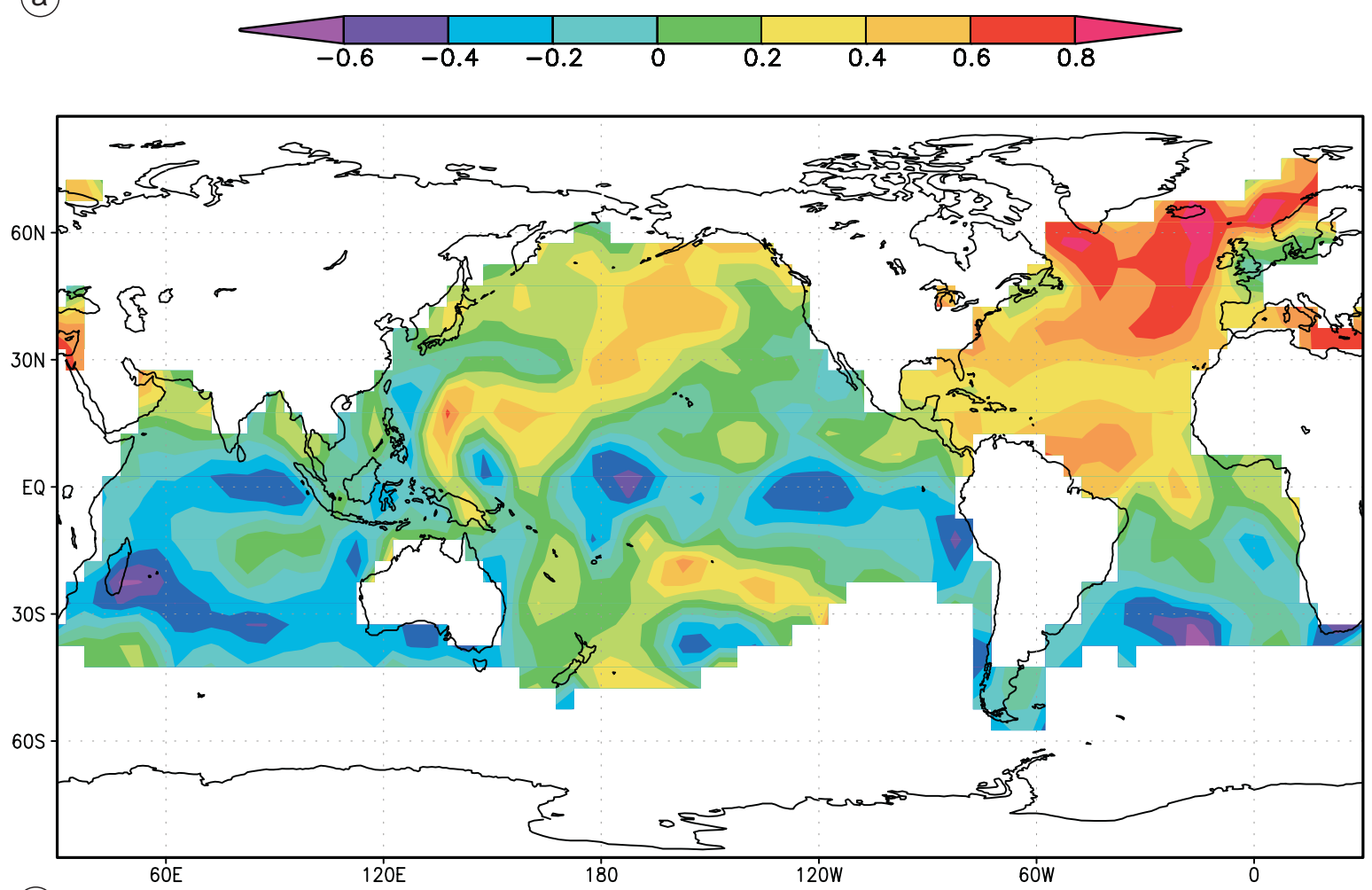

(b)

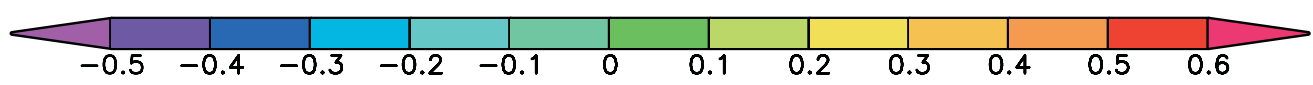

Fig. 7a,b. a) Spatial distribution of correlation coefficients between the Niño-3 SST anomaly time series and the global SST anomalies at zero lag. b) Spatial distribution of correlation coefficients between the Niño-3 SST anomaly time series and the global SST anomalies at lag 30 years. The anomaly structure in (b) is reminiscent of variations in the THC, indicating that variations in the THC follow variations in tropical Pacific SST with a time lag of 30 years. The data were low-pass filtered with a 11-year running mean prior to the correlation analyses. 
salinitiy observations taken at Bermuda $\left(33^{\circ} \mathrm{N}\right.$, $\left.65^{\circ} \mathrm{W}\right)$. A strong increase in the surface salinity is observed during the last few decades (fig. 6), which is expected given the strong increase in tropical Pacific SST and the decrease of tropical Atlantic (model) freshwater flux during the recent decades. These trends may continue in response to greenhouse warming as hypothesised above.

In the next step, it is investigated whether the THC in the Atlantic responds to the variations in the freshwater flux. This can be done only indirectly by using SSTs, since the required direct observations of the freshwater flux, surface salinity, and the THC do not exist. Ocean model and coupled model studies have shown that variations in the THC are associated with changes in the poleward ocean heat transport and an interhemispheric SST dipole (see, e.g., Manabe and Stouffer, 1999 and references therein). Thus, this characteristic SST anomaly pattern can be used as a «fingerprint» to identify variations in the real THC. A correlation analysis was conducted using the Kaplan SST data set. First, the zero-lag correlation of the low-pass filtered tropical Pacific (Niño-3) SST anomaly time series with the global SST anomaly field has been computed. The resulting correlation pattern (fig. 7a) shows the well known picture in the tropical Pacific, with an El Niño-like positive signal in the eastern and central equatorial Pacific and negative anomalies in the mid-latitudes of both hemispheres. A teleconnection to the Indian Ocean can be seen also, a feature known from present-day El Niño events. Strong negative correlations are found in the North Atlantic near Greenland, which is consistent with the recent increase of the North Atlantic Oscillation.

Based on the arguments described above, the time it will take to develop sufficiently strong salinity anomalies and to transport those poleward into the so called «sinking region» in the high latitudes is of the order of a few decades. Therefore, a time lag of 30 years has been introduced in the correlation analysis. The results of this lagged correlation analysis (fig. 7b) exhibit strongest signals in the Atlantic Ocean, although a tropical Pacific SST index has been used as reference. The SST anomaly pattern is the interhemispheric dipole identified in model studies to go along with changes in the THC (see, e.g.,
Schiller et al., 1997). Anomalously warm temperatures are found in the northern part and anomalously cold temperatures in the southern part of the Atlantic Ocean. Thus, the results indicate that interdecadal changes in tropical Pacific SST are followed by basin-wide changes in Atlantic SST, and that periods of high (low) SSTs in the eastern tropical Pacific are followed by a strong (weak) THC in the Atlantic. The statistical significance of the results was tested using a $t$-test and assuming 10 degrees of freedom, and correlations above about 0.5 are significant at the $95 \%$ level. More important than the level of the significance, however, is the fact that physically motivated SST anomaly patterns result from the two correlation analyses.

\section{Concluding remarks}

The tropical air-sea interactions that stabilise the thermohaline circulation in our model simulation are not adequately represented in most global climate models applied hitherto to the problem of anthropogenic climate change, mainly because of their too coarse resolution in the tropics. This feedback needs to be studied more carefully in relation to the destabilising feedbacks considered in previous investigations. At this stage of analysis we can conclude only that the response of the THC to enhanced greenhouse warming is still an open question. The uncertainty arises from model shortcomings in the representation of key physical processes, such as the hydrological cycle. Our results may be important also in view of multi-decadal and paleoclimatic variations, because they indicate that variations in the tropics may synchronise changes globally. The hypothesis of the tropical influence on the THC is very difficult to verify by observations. There is, however, some observational evidence that multi-decadal variations in the tropical Pacific SST feed back on the North Atlantic THC.

\section{Acknowledgements}

I would like to thank U. Mikolajewicz, J. Oberhuber and E. Roeckner. This work was supported by the European Union's SINTEX project. 


\section{REFERENCES}

BACHER, A., J.M. OberhUbeR and E. RoECKNER (1997): ENSO dynamics and seasonal cycle in the tropical Pacific as simulated by the ECHAM4/OPYC3 coupled general circulation model, Climate Dyn., 14, 431-450.

BROECKER, W.S. (1991): The great ocean conveyor, Oceanography, 4, 79-89.

Broecker,W.S., D.M. PeteEt and D. RIND (1985): Does the ocean-atmosphere system have more than one stable mode of operation?, Nature, 315, 21-26.

Christoph, M., T.P. BARNETT and E. ROECKNER (1998): The Antarctic Circumpolar Wave in a Coupled OceanAtmosphere GCM, J. Climate, 11, 1659-1672.

Cubasch, U., K. Hasselmann, H. HÖCK, E. MaierReimer, U. Mikolajewicz, B.D. SANTER and R. SAUSEN (1992): Time-dependent greenhouse warming computations with a coupled ocean-atmosphere model, Climate Dyn., 8, 55-69.

Delworth, T., S. MANABE and R.J. StOufFer (1993): Interdecadal variations of the thermohaline circulation in a coupled ocean-atmosphere model, J. Climate, 6 , 1993-2011.

IPCC (1992): Climate Change 1992: the Supplementary Report to the IPCC Scientific Assessment, edited by J.T. Houghton, B.A. CAllander and S.K.V. VARneY (Cambridge University Press), pp. 200.

Kaplan, A., M.A. Cane, Y. KushniR, A.C. Clement, M.B. BLUMENTHAL and B. RAJAGOPALAN (1997): Analyses of global sea surface temperature 1856-1991, J. Geophys. Res., 102, 27,835-27,860.

LAU, N.-C. (1985): Modeling the seasonal dependence of the atmospheric responses to observed El Niños 19621976, Mon. Weather Rev., 113, 1970-1996.

LATIF, M. (2001): Tropical Pacific/Atlantic Ocean Interactions at multi-decadal time scale, Geophys. Res. Lett., 28, 539-542.

LATIF, M., E. RoECKNER, U. Mikolajewicz and R. Voss (2000): Tropical stabilisation of the thermohaline circulation in a greenhouse warming simulation, $J$. Climate, 13, 1809-1813.

Manabe, S. and R.J. STOUfFER (1994): Multiple-century response of a coupled ocean-atmosphere model to an increase of atmospheric carbon dioxide, J. Climate, 7, 5-23.

MANABE, S. and R.J. STOUFFER (1995): Simulation of abrupt climate change induced by freshwater input to the North Atlantic Ocean, Nature, 378, 165-167.

MAnABE, S. and R.J. Stouffer (1999): The role of thermohaline circulation in climate, Tellus, 51, 91-109.

MAnABE, S., R.J. StOUfFER, M. SPELMAN and K. BRYAN (1991): Transient responses of a coupled oceanatmosphere model to gradual changes of atmospheric $\mathrm{CO}_{2}$, part I, annual mean response, J. Climate, 4, 785818.

Mikolajewicz, U. and R. Voss (2000): The role of the individual air-sea flux components in $\mathrm{CO}_{2}$-induced changes of the ocean's circulation and climate, Climate Dyn., 16, 627-642.

Mikolajewicz, U., B.D. SAnter and E. Maier-Reimer (1990): Ocean response to greenhouse warming, Nature, 345, 589-593.
NEELIN, J.D. and H.A. DIJKSTRA (1995): Ocean-atmosphere interaction and the tropical climatology. Part I: the dangers of flux correction, J. Climate, 8, 1325-1342.

Oberhuber, J.M., E. RoECKNER, M. CHRISTOPH, M. ESCH and M. LATIF (1998): Predicting the ' 97 El Niño event with a global climate model, Geophys. Res. Lett., 25, 2273-2276.

PARKER, D.E., M. JACKSON and E.B. HORTON (1995): The GISST 2.2 sea surface temperature and sea ice climatology, Climate Research Technical Note 63, Hadley Centre, Meteorological Office, Bracknell, U.K., pp. 35 .

PHILANDER, S.G.H. (1990): El Niño, La Niña and the Southern Oscillation (Academic Press, San Diego), pp. 293.

RAHMSTORF, S. (1995): Bifurcations of the Atlantic thermohaline circulation in response to changes in the hydrological cycle, Nature, 378, 145-149.

RAHMSTORF, S. (1997): Risk of sea-change in the Atlantic, Nature, 388, 825-826.

RAHMSTORF, S. (1999): Shifting seas in the greenhouse?, Nature, 399, 523-524.

RoECKNER, E., J.M. OBERHUBER, A. BACHER, M. CHRISTOPH and I. KIRCHNER (1996): ENSO variability and atmospheric response in a global atmosphere-ocean GCM, Climate Dyn., 12, 737-754.

RoECKNER, E., L. BENGTSSON, J. FEICHTER, J. LELIEVELD and H. RoDHE (1999): Transient climate change simulations with a coupled atmosphere-ocean GCM including the troposheric sulfur cycle, J. Climate, 12, 3004-3032.

ROPELEWSKI, C.F. and M. HALPERT (1987): Global and regional scale precipitation patterns associated with the El Niño/Southern Oscillation, Mon. Weather Rev., 115, 1606-1627.

SCHILlER, A., U. MiKOLAJEWICZ and R. Voss (1997): The stability of the thermohaline circulation in a coupled ocean-atmosphere model, Climate Dyn., 13, 325-348.

SCHMITTNER, A., C. APPENZELLER and T.F. STOCKER (2000): Enhanced Atlantic freshwater export during El Niño, Geophys. Res. Lett., 27, 1163-1166.

STOCKER, T.F. and D.G. WRIGHT (1991): Rapid transitions of the ocean's deep circulation induced by changes in surface water fluxes, Nature, 351, 729-732.

Timmermann, A., M. LATIF, R. Voss and A. GROETZNER (1998): Northern Hemisphere interdecadal variability: a coupled air-sea mode, J. Climate, 11, 1906-1931.

Timmermann, A., J. OBerhuber, A. BACHER, M. EsCH, M. LATIF and E. ROECKNER (1999): Increased El Niño frequency in a climate model forced by future greenhouse warming, Nature, 398, 694-697.

Ulbrich, U. and M. CHRISTOPH (1999): A shift of the NAO and increasing storm track activity over Europe due to anthropogenic greenhouse gas forcing, Climate Dyn., 15, 7, 551-559.

WoOd, R.A., A.B. KEEN, J.F. MitChELl and J.M. GREGORY (1999): Changing spatial structure of the thermohaline circulation in response to atmospheric $\mathrm{CO}_{2}$ forcing in a climate model, Nature, 399, 572-575.

ZHANG, X.-H., J. OBERHUBER, A. BACHER and E. ROECKNER (1998): Interpretation of interbasin exchange in an isopycnal ocean model, Climate Dyn., 14, 725-740. 